\title{
Turismo, gentrificação urbana e (des) alojamento local na cidade de Lisboa - Portugal
}

\author{
Tourism, urban gentrification and local (dis)lodging in Lisbon - Portugal
}

\author{
Solismar Fraga Martins ${ }^{\mathbf{I}}$
}

\section{RESUMO}

Esta pesquisa tem como objetivo analisar o aumento significativo do turismo na cidade de Lisboa aliado a novas práticas de gentrificação e de hospedagem, e as decorrentes alterações no modo de vida dos moradores, principalmente nos bairros históricos. Isso traz como resultado o aumento do valor do metro quadrado dos imóveis para venda e para aluguel anual, causando o desalojamento dos arrendatários e sua substituição por ocupação de curta permanência e maior rentabilidade. Buscaram-se referenciais teóricos basilares nessa temática, assim como autores portugueses e espanhóis que se dedicam a este assunto. Os dados empíricos foram obtidos através de fonte documental e jornalística sobre o tema, dada a sua frequência na imprensa e a relevância que tem hoje para os habitantes.

Palavras-chave: Alojamento local; Gentrificação; Lisboa; Reabilitação; Turismo

\section{ABSTRACT}

This is an analysis on the significant increase of tourism in Lisbon associated to new forms of gentrification and hospitality, and the consequent changes in living style of the inhabitants, mainly in historic districts. As a result, prices of built area increase both for annual rental and for sale, and long-time residents do not find rental housing in these areas. This research includes basic theoretical references as well as Portuguese and Spanish authors on this matter. Empirical data were obtained from documental and press sources, since this is a frequent and relevant issue for inhabitants.

Keywords: Hospitality; Gentrification; Lisbon; Rehabilitation; Tourism.

\section{INTRODUÇÃO}

O trabalho ora apresentado faz parte de uma pesquisa de pós-doutorado realizada na Universidade de Lisboa que compreende práticas de gentrificação urbana, espaços industriais desativados e turismo. O presente artigo visa analisar os aspectos relativos ao processo de desenvolvimento turístico verificado na cidade de Lisboa na última década, o crescimento do alojamento local alternativo à hotelaria e a valorização imobiliária que disso decorreu. Tal conjuntura permitiu a suba significativa do valor dos imóveis nesta cidade e a consequente expulsão de todos aqueles que não detinham renda para poder acompanhar o aumento dos valores na

IProfessor Associado IV do Instituto de Ciências Humanas e da Informação, Universidade Federla do Rio Grande, Rio Grande, RS. Email: solismarfm@terra.com.br ORCID: http://orcid.org/0000-0002-9240-4090 
alocação dos imóveis. Em contraponto à alocação anual, as locações diárias e semanais propiciam maiores ganhos aos proprietários e representam um dos tipos favoritos de hospedagem nesta cidade para os turistas, aliado à tradicional rede hoteleira. Ao abordar conceitos de gentrificação, recorremos a autores clássicos na temática, como Neil Smith e Ruth Glass, mas também autores que vêm atualizando tais conceitos e metodologias de análise, como Augustin Gant, Luis Mendes e Jorge Gonçalves. Estes trazem abordagens relacionadas a práticas de reabilitação e requalificação urbanas, assim como ao desenvolvimento do alojamento local como forma de hospedagem que está relacionada diretamente aos processos de gentrificação. Novos procedimentos facilitadores da locação através de aplicativos, pagamentos on line correlacionados e avaliação contínua e pública dos espaços de hospedagem também fazem parte destas novas modalidades de alojamento temporário. Os dados relativos aos valores dos imóveis foram obtidos através de fontes documentais, como relatórios da Câmara de Lisboa, além de artigos de revistas e jornais que vêm tratando esse tema de forma corrente na imprensa portuguesa, devido aos impactos causados por esse processo de turismo e gentrificação nos bairros históricos da cidade.

\title{
2 A CORRELAÇÃO DO TURISMO, GENTRIFICAÇÃO E O (DES)ALOJAMENTO DE MORADORES LOCAIS
}

Entendem-se como gentrificação urbana os processos de reabilitação e requalificação, isolados ou associados, que visam à alteração e nobilitação de centros históricos ou mesmo outras áreas, como antigos prédios industriais. Gonçalves (2003, p. 70) assim define tais processos:

\begin{abstract}
Reabilitação urbana: processo de transformação do espaço urbano compreendendo a execução de obras de conservação, recuperação e readaptação de edifícios e de espaços urbanos, com o objectivo de melhorar as suas condições de uso e habilidades, conservando, porém, o seu carácter fundamental. Requalificação tem sido, usualmente, aplicada a espaços públicos degradados ou disfuncionais como sejam as frentes de mar ou ribeirinhas ou os antigos terreiros de feiras e festas, tão comuns nas médias cidades. Trata-se, sobretudo, de intervenções públicas na melhoria dos espaços, dotando-os de condições para novos espaços colectivos de recreio e lazer.
\end{abstract}

O termo gentrificação foi utilizado pela primeira vez por Ruth Glass, em 1964 (SMITH, 1996, p. 20; PAVEL, 2015, p. 70), e é definido como uma mudança da 
posição econômica de um lugar sob o ponto de vista do mercado imobiliário, e que vem a transformar também os serviços existentes, assim como a qualidade física e suas características sociais. Segundo Smith (1996, p. 17) e Pavel (2015, p. 70), o processo de gentrificação pode ser apresentado em três etapas sucessivas: a primeira tem início em 1964, estende-se até a década de 1980 e não detém uma planificação; a segunda começa na década de 1980 e é também conhecida como fase de ancoragem, pois passa a ganhar sistematização; somente a partir da metade da década de 1990 inicia-se a terceira fase, que ganhará contornos mais globais como característica principal. Segundo Smith (1996, p. 25), a gentrificação concebida numa perspectiva marxista analisa o processo de desvalorização do imóvel, que, no entanto, se contradiz com o valor do solo urbano a partir de uma determinada conjuntura. Quando isso ocorre, o que representa a base do processo de gentrificação, o valor do investimento que ocorrerá naquele espaço tem como referência o lucro futuro que poderá render, ao conciliar potencial turístico e cultural e nobilitação urbana. Os lugares propícios a esse processo são comumente sítios históricos, e como tal devem ser preservados em suas fachadas, mesmo que em determinadas situações apenas estas restem das antigas construções. Então entram em cena processos de reabilitação e requalificação urbana. Quando tal processo se desenvolve aparece o que se denomina de rent-gap.

Forma-se, deste modo, aquilo a que Smith chama de rent-gap, que o autor considera como a causa principal da gentrificação. Para o autor, é esta rent-gap, diferença entre o valor atual e o valor potencial do imóvel, que determina a existência, ou não, de potenciais lucros no investimento na área (PAVEL, 2015, p. 76).

Os processos de gentrificação urbana e exploração turística, nas últimas décadas, principalmente, passaram a atuar conjuntamente em diferentes cidades e vêm extrapolando cada vez mais aqueles espaços tradicionais que se convencionaram como locais turísticos. Comumente tais lugares estão/estavam relacionados a balneários, cidades serranas ou cidades de importância histórica e arquitetônica que há muito tempo representavam destinos turísticos internacionais. Não que nestes lugares tenha diminuído o fluxo de turistas, já que o processo de gentrificação tem causado a expulsão dos moradores locais, substituídos pelo alojamento para turistas. É premente destacar a ampliação de novos lugares que ingressam numa rota global turística e que, alinhada com processos de gentrificação, adquire intervenções mais 
incisivas nas últimas décadas do século $X X$, trazendo a ideia de uma nova fronteira e de um novo protagonismo que legitime práticas urbanas.

Como em toda ideologia, existe uma base real e parcial, embora distorcida, para o tratamento da gentrificação como nova fronteira urbana. A fronteira representa uma combinação evocativa de avanços econômicos, geográficos e históricos, e ainda o individualismo social preso a este destino é, em um aspecto muito importante, um mito (SMITH, 1996, p. 17). ${ }^{\text {i }}$

O que há de novo nesse processo é a maior movimentação de pessoas em busca de entretenimento no mundo e a introdução de novos elementos que baixam os custos das viagens e possibilitam que uma maior parcela de população possa se deslocar. Tudo isso representa um ponto positivo quando pensamos na possibilidade de um maior número de pessoas a viajar e conhecer novos lugares; no entanto, se o universo de turistas tem aumentado progressivamente, os lugares a recebê-los estão vinculados aos velhos sítios históricos e/ou turísticos de cunho ambiental-paisagístico, e que não cresceram na mesma proporção desse fluxo turístico. Se tínhamos até o começo do século presente a predominância das redes hoteleiras como locais de alojamento para o fluxo turístico, e isso representava sempre um maior valor agregado na despesa de hospedagem, hoje encontram-se novas formas de alojamento, que tendem a baratear o custo da viagem, assim como proporcionar espaços mais descontraídos e próximos da vivência de suas residências. Estamos falando de alojamentos como hostels e o que se convencionou denominar em Portugal e adotamos neste texto como alojamento local.

Alojamento local refere-se ao aproveitamento de residências em que vivem pessoas diariamente, para hospedagem de turistas em estadas curtas, comumente menos do que um mês, correspondendo a semanas ou a partir de dois dias, embora isso não represente uma regra. Tais espaços podem ser tanto o imóvel inteiro, seja um apartamento, uma casa ou um imóvel rural, ou mesmo fragmentos destes como um cômodo ou mesmo um leito em quarto compartilhado. O alojamento local alterou substancialmente as práticas de gentrificação urbana e deu novos contornos a um processo que se acelerou de forma sem precedentes.

É um processo de bola de neve no qual a área perde moradores e exclui os potenciais da possibilidade de mudança. Isso leva a uma forma de deslocamento coletivo nunca vista na gentrificação clássica, ou seja, a uma substituição da vida residencial pelo turismo (GANT, 2016, 52). ii 
A prática do alojamento local talvez seja mais antiga que a própria hotelaria. Entretanto, ganhou importância econômica com o advento da Internet. Plataformas de gerenciamento dessa atividade - a mais conhecida é AirBnb - pressupõem o alojamento local como um espaço de convívio compartilhado e otimização de recursos.

A AirBnb foi criada em 2008 e hoje é de conhecimento público que esse setor vem atraindo cada vez mais e de forma recente, grandes investidores de maior envergadura financeira e que atuam como redes em determinadas cidades. Isso retirou em parte aquele sentido mais pitoresco e nostálgico de compartilhamento de uma moradia como se estivéssemos hospedados na casa de parentes ou amigos. Uma propaganda utilizada pela Booking, hoje principal concorrente da AirBnb, apresentava no metrô de Lisboa um cartaz com os seguintes dizeres: "Trabalhe menos. Viaje mais. Alugue sua casa". A propaganda atinge de forma plena o espírito daquilo que se busca demonstrar.

$\mathrm{Na}$ atualidade, freguesias ${ }^{\mathrm{iii}}$ inteiras de cidades como Lisboa vêm sendo impactadas por esta mudança, na qual antigos moradores foram sendo desalojados, principalmente a partir de alteração da legislação portuguesa promovida em 2012. Esses processos já vinham ocorrendo com maior velocidade e truculência em cidades como Barcelona (GANT, 2016, p. 3; GANT, 2017, p. 8; GANT, 2018, p. 2), cujos bairros históricos vêm perdendo população devido à concorrência pela disputa de espaços para morar. Mesmo outras atividades não residenciais, como comércio e serviços de capital local, passam a se direcionar para o consumidor e turista e pouco têm a ver com as necessidades dos habitantes locais (GUIMARÃES, 2018, p.10).

A primeira medida de impacto ocorre sobre moradores que dependem de arrendamento anual, pois atividades que aliam turismo e práticas de gentrificação acabam por expulsar esses residentes devido à elevação dos valores dos imóveis que passam a ser remodelados, e acima de tudo "modernizados". Tudo isso visa ao atendimento de uma demanda crescente de pessoas dispostas a pagar valores diários muitíssimo superiores àqueles que um morador pode despender para um arrendamento anual. Para Gant (2016, p. 44), "Simplificando, os aluguéis de curto prazo são uma oportunidade comercial atraente, assim como os residentes de longo prazo representam uma barreira à acumulação de capital". iv 
Em cidades balneárias e lugares turísticos por excelência, sempre foi comum haver imóveis que eram arrendados com fim turístico e de curta duração. No entanto, o aumento exponencial do fluxo turístico e a eleição de novos lugares como cidades da moda para o turismo internacional (SMITH, 2006, p. 23) fazem com que os valores dos imóveis tenham uma elevação muito superior à capacidade da população residente portuguesa em pagar tais arrendamentos, assim como superior aos próprios índices de aumento salarial anual. Enquanto o salário mínimo português em 2018 é de 580 euros e com aumento anual entre quatro a cinco por cento no último quadriênio, os valores dos imóveis para compra em Lisboa têm atingido índices próximos a $20 \%$ de acréscimo ao ano (GOMES, 2018, p. 39). Esse aumento no valor dos imóveis foi facilitado por mudanças na legislação portuguesa. Uma delas referese à flexibilização nas normas de arrendamento para Portugal a partir de 2012, por meio da chamada Lei Christas (Lei n. 31/2012, de 14 de agosto), que pôs fim a uma legislação sobre arrendamentos e denominada de congelamento das rendas. Esta, de origem remota, fez com que hábitos culturais de famílias que arrendam imóveis durante décadas, hoje algo raro em países como o Brasil, tornassem prédios inteiros como objeto de rendas e muitas vezes tendo um único proprietário. Essa nova situação facilita muito ao comprador e permite que os prédios sejam adquiridos por grandes empresas, redes de hotéis, seguradoras e outras tipologias empresariais, que passam a reformar todo o prédio com o único objetivo de transformá-lo em alojamento local.

Porém, tais construções, antes da reforma na legislação, detinham inquilinos que moravam ali havia muitos anos. Podemos afirmar que, tanto em Lisboa como em Portugal de um modo geral, era/é comum uma família estar morando há décadas no mesmo imóvel por aluguel e com o mesmo proprietário. Com a substituição dos moradores locais por turistas de temporada, os tradicionais bairros históricos vão perdendo suas características originais através da perda de sua identidade dada por seus habitantes. A forma de ser, de vestir e de viver acaba por ser substituída por uma massa crescente de turistas que perambulam por esses lugares em busca de novidades e divertimento, além da transitoriedade na forma de ocupação de apartamentos por dois, três ou mais dias que, comumente, acaba por perturbar a vida cotidiana daqueles que ali ainda vivem. 
O processo é alimentado por investidores, empresas de turismo e proprietários individuais, para quem a conversão de edifícios residenciais em alojamento para visitantes é uma nova oportunidade de negócio. É também facilitado pelo estado através da liberalização do mercado imobiliário, uma vez que permite essa conversão. Em contraste, para os residentes e para aqueles que precisam de um lugar para morar, as férias representam a nova frente de batalha da gentrificação. O fenômeno ameaça seu direito de ali permanecer, ao mesmo tempo em que dificulta cada vez mais que os moradores encontrem acomodações acessíveis (GANT, 2016, 6.1).

Um outro impacto que o turismo aliado à gentrificação proporciona refere-se à expulsão das antigas atividades comerciais existentes nesses bairros históricos. 0 aumento exponencial dos valores cobrados nos aluguéis torna inviável o desenvolvimento de suas atividades e gradativamente ocorre a substituição por atividades comerciais ligadas às grandes redes de fast food e côngeneres, vestuário e outras que estejam adequadas ao novo padrão de consumo imposto àquela localidade. Isso torna o custo de permanência da atividade inviável, devido ao valor crescente do arrendamento do imóvel. Por outro lado, tais lugares atraem novos moradores sequiosos de usufruir esses espaços e compartilhar tais experiências.

O novo ambiente que as lojas modernas trazem para os distritos é bem-recebido pelos residentes e pelos usuários tradicionais. Residentes vêem um ambiente de varejo contemporâneo em sua área, mesmo que não tenham a intenção de comprar nessas lojas ou não possam pagar por seus produtos. Como sugerido, para os moradores com menos recursos, a abertura dessas novas lojas não os beneficia porque eles não têm condições de comprar o que elas vendem. Além disso, esse cenário pode valorizar toda a área, aumentando os aluguéis e causando o deslocamento das poucas lojas em que os menos abastados podem comprar (GUIMARÃES, 2018, p. 6). v

As mais novas formas de comunicação por Internet e aplicativos, aliadas ao uso das facilidades de pagamento por cartão de crédito de forma on line, agilizam o processo de arrendamento em qualquer lugar do planeta onde tais recursos estejam disponíveis. Isso permite que seja feita uma transação de arrendamento por curto período de um imóvel em qualquer lugar. Ali encontram-se todas as características de localização do imóvel, aspectos estruturais, características de mobília e equipamentos e ainda os comentários dos últimos hóspedes sobre o imóvel.

Essas facilidades, oferecidas hoje em sites como AirBnb e Booking, as duas maiores operadoras do setor, são recentes e se distanciam muito da forma de se fazer turismo até o final do século $X X$, através de agências de viagem e rede hoteleira. A hospedagem de custo ainda mais baixo, oferecida pelos hostels, permite um fluxo cada vez maior de turistas, principalmente um público mais jovem, que 
pode se deslocar com maior facilidade em busca de lazer. Devemos levar em conta também que o novo perfil de classe média que hoje encontramos se coaduna muito bem ao do turista que busca a cultura e o lazer como elementos-chaves na sua forma de vida.

Se na modernidade a busca por acumular riqueza e constituir renda, comprar imóvel e veículos representava o sonho muito espelhado pelos filmes norteamericanos, hoje a classe média pós-moderna detém outros objetivos. As novas famílias de classe média hoje fogem do velho formato da família burguesa, e isso representa um aspecto positivo no sentido de escapar aos estereótipos. Essa nova classe média está mais aberta também a novos prazeres e lazeres de não somente visitar aquilo que representa a cultura de um povo, mas de preferência inserir-se nesses espaços, seja como turistas de curto período, seja em vivências e temporadas mais longas em muitos casos.

Nesse processo encontraremos também um retorno não de turistas de curta ou moradores de média duração por temporadas, mas de novos moradores que irão ocupar os velhos sítios históricos das cidades, ou seja, o retorno após décadas do abandono que tinha sido propiciado por gerações anteriores à sua (MENDES, 2006, p. 72).

Indissociável da cultura de consumo e da emergência e crescimento de atividades de produção simbólica, encontra-se também a afirmação de uma tendência de estetização da vida social. Esta pode ser entendida em vários sentidos. Em primeiro lugar, o do "apagamento" ou transgressão dos limites entre a arte e a vida social.

É a ideia de que tudo pode ser arte e de que a arte pode estar embutida em todo e qualquer objeto, manifestação, comportamento, incluindo na trivialidade da vida quotidiana. Em segundo lugar, a estetização da vida social pode ser entendida como o projeto de tornar a vida uma obra de arte - salientem-se as figuras do dandy, do flâneur, personificações do estilo de vida boêmio e que privilegia as sensações e as experiências de vida na produção do entendimento da realidade social. Há outra diferença entre o perfil da classe média tradicional (a da modernidade) e o da nova classe média (a da pós-modernidade): para a classe média moderna, o futuro era algo a ser perseguido, buscado mesmo sem saber o que isso significasse; já a nova classe média, contraditoriamente, volta-se para o passado pela insegurança daquilo que representa o futuro. Nesse caso entram em cena os velhos sítios históricos e 
ganham força como elemento ideológico de consumo do espaço, ao estarem aliados aos novos precursores de exploração dos centros históricos das velhas cidades e na homogeneização do consumo do e no espaço. Isso ocorre não no sentido de retirada daquilo que o lugar tem de único, mas na homogeneização interna dos espaços, a fim de padronizar os locais de alojamento local e fazer com que, acima de tudo, esse turista se sinta em casa. Mendes (2006, p. 60) mostra como isso vem ocorrendo no Bairro Alto ${ }^{\text {vi }}$ da cidade de Lisboa:

Recorrendo, embora, ao Bairro Alto como caso ilustrativo, daremos particular atenção às formulações teóricas que reconhecem na recomposição socioespacial encetada pela nobilitação urbana, transformações mais vastas, tributárias da produção da cidade pós-moderna. Em especial, daquelas que são iniciativa de determinados grupos sociais, do seu todo ou em parte, e que vão de encontro a uma valorização do consumo simbólico - que se estende doravante dos objectos aos territórios - e a estilos de vida suportados pelos privilégios associados à centralidade urbana. Movimento esse que é, por sua vez, favorável à estetização dos ambientes urbanos quotidianos e da vida social. Esta ideia aproxima-se das descrições que têm vindo a ser feitas da cidade pós-moderna como espaço privilegiado de consumo de mercadorias, imagens e estilos de vida, em contraste com a cidade moderna, que se definia primordialmente em função do seu papel na produção industrial (MENDES, 2006, p. 60).

É importante ressaltar que o conceito de família hoje se alterou e é muito mais diversos em sua composição do que a tradicional família burguesa, sendo que este novo perfil de pessoas que buscam o prazer transitório, a jouissance, afina-se com os objetivos dos gentrifiers que estão disponíveis para proporcionar essa aproximação das pessoas com os lugares. Entretanto, isso significa a expulsão dos antigos moradores, já que os novos hotéis, hostels, assim como outras formas de alojamento local, não irão se instalar na periferia das cidades, mas sim nos velhos centros históricos ou em pequenas cidadelas muradas, vilas de pescadores detentoras de praias com potencial turístico, ou mesmo em zonas históricas de metrópoles, como é o caso da cidade de Lisboa.

As mudanças na estrutura da sociedade como o aumento da participação das mulheres no trabalho e a subida a cargos de liderança nas organizações; o crescimento de uniões de facto e o adiar crescente da idade do casamento; o aumento do número das famílias monoparentais; a emergência de novos modelos de família; o crescimento da taxa de divórcios, são algumas das novas tendências determinantes na escolha de residência. $O$ centro da cidade tornou-se escolha preferencial para grupos que apreciam o modo de vida urbano, e que aliam a residência à proximidade do local de emprego. Estes novos trabalhadores de colarinho branco afirmam-se por um novo estilo de vida. $O$ valor arquitetônico do edificado no centro de muitas cidades, e as mudanças no perfil dos residentes de muitos bairros tradicionais, estão na base do aparecimento de novas políticas urbanas (ROMANA, 2006, p. 7). 


\title{
3 PRÁTICAS DE GENTRIFICAÇÃO RECENTES NA CIDADE DE LISBOA
}

Em Lisboa verifica-se uma significativa mudança nos últimos anos quanto ao aumento do número de imóveis disponibilizados para alojamento local, assim como o aumento acentuado no valor do metro quadrado dos imóveis nas diferentes freguesias que compõem a cidade. $O$ crescimento vertiginoso do número de alojamentos locais em detrimento do aluguel anual, e em consequência o desalojamento de famílias que sempre viveram nessa cidade e que hoje buscam outros locais mais afastados para viver, vem sendo registrado em diferentes órgãos de comunicação do país, assim como tem levantado intensos debates na Assembleia da República e na Assembleia Municipal de Lisboa. A Associação do Alojamento Local em Portugal (ALEP) informa que tal atividade emprega em torno de dez mil pessoas na cidade de Lisboa, embora não tenha disponibilizado dados sobre a setorização desses empregos, assim como os rendimentos que proporcionam. Conforme Fernandes (2017, p. 1), há quatro tipos de agentes que atuam neste momento no setor:

\begin{abstract}
Promotores, que constroem edifícios de apartamentos e que os vendem em frações, assegurando a gestão da operação (ex: Coporgest/Lisbon Best Apartments ou Habitat Vitae - Five Stars/Lisbon Downtown Lovers); Proprietários Operadores, que promovem e exploram os seus edifícios de apartamentos (ex: Heritage Apartments ou Lisbonaire Apartments); Operadores, que gerem várias unidades de alojamento que são propriedade de terceiros (ex: Feels Like Home, Lisbon Serviced Apartments, Portugal Exclusive Homes) e ainda múltiplos operadores individuais que gerem os seus próprios apartamentos.
\end{abstract}

Registre-se que o número de alojamentos locais em Portugal para o ano de 2010 era de 4.895 ofertas, enquanto em 2018 a previsão é de que atinja 68.827 imóveis. Para o Distrito de Lisboa (envolve sua região metropolitana, incluindo as freguesias mais antigas da cidade e que detêm valor histórico-patrimonial), encontramos para 2018, 17.261 imóveis disponíveis como alojamentos locais (GOMES, 2018, p. 42-43). Portugal tem pouco mais de 10 milhões de habitantes e uma malha urbana concentrada, sobretudo, no litoral do país e, principalmente, nas regiões metropolitanas das duas maiores cidades: a região metropolitana de Lisboa e a do Porto, ambas detentoras de populações superiores a dois milhões de habitantes cada.

A crise portuguesa, dentro de uma crise maior europeia que assolou muitos países em 2008, teve nas atividades do turismo um importante fator para sua 
recuperação. Neste caso, cidades como Lisboa e Porto e a região do Algarve se tornaram os principais polos irradiadores do turismo em Portugal. Deve ser destacado que os atributos turísticos histórico-arquitetônicos e natural-paisagísticos sempre estiveram nesses lugares, mesmo considerando que a estrutura para receber os turistas estivesse aquém da que o país apresenta na atualidade.

Figura 1 - Mapa das freguesias de Lisboa



Fonte: Câmara Municipal de Lisboa

No entanto, alteraram-se as estratégias na venda da imagem de um país seguro, no que diz respeito a não ter registrado em sua recente história atentados terroristas, assim como a manter baixos índices de violência urbana. Outros fatores também interferiram positivamente para o aumento do fluxo turístico: a proximidade dos demais países europeus; o grande número de dias ensolarados, típicos de um país localizado ao sul da Europa; e o custo de vida mais baixo do que em outros países do velho continente. No caso de Lisboa, são as freguesias históricas as mais procuradas pelos turistas para se alojar, assim como por aqueles que pretendem 
permanecer (ver figura 1): localizadas junto ao Rio Tejo, a partir da freguesia da Estrela, até a freguesia de São Vicente, incluindo as freguesias da Misericórdia, de Santa Maria Maior e, mais afastadas da zona ribeirinha, as freguesias históricas de Santo Antônio e Arroios. Fora da área histórica tradicional de Lisboa, encontramos procura pelas freguesias típicas de classe média nesta cidade, mas mais afastadas da ribeira e da área histórica, como as freguesias de Campolide, Avenidas Novas e Alvalade, sendo nestas últimas com menor peso a característica históricoarquitetônica, embora também a possuam. Já a freguesia do Parque das Nações, antiga área industrial de Lisboa, após vivenciar um período de decadência industrial e abandono do espaço urbano, passou por um processo de regeneração para a Expo 98 e acabou por se configurar numa outra proposta urbanística. O sucesso do empreendimento resultou numa atração da classe média alta de Lisboa para essa freguesia, que, mesmo estando distante dos bairros históricos, encontra-se próxima do aeroporto e acabou por criar uma nova urbanidade como polo concentrador de atividades residenciais, comerciais, de transporte e lazer (MACHADO, 2006, p. 87).

No quadro a seguir encontramos as freguesias de Lisboa, de forma decrescente, enumeradas conforme o número de alojamentos disponíveis (até 30 de junho de 2018) e o valor do metro quadrado para venda em junho de 2018.

Quadro 1 - Número de alojamentos locais e valor por metro quadrado para venda por freguesia na Cidade de Lisboa

\begin{tabular}{|c|c|c|c|}
\hline No $^{\circ}$ & NOME DA FREGUESIA & $\begin{array}{c}\text { No ALOJAMENTOS } \\
\text { (dados a 30 de junho de 2018) }\end{array}$ & $\begin{array}{c}\text { VALOR DO M }^{2} \\
\text { (em euros) }\end{array}$ \\
\hline 1 & Santa Maria Maior & 3.299 & 3.528 \\
\hline 2 & Misericórdia & 2.736 & 3.667 \\
\hline 3 & Arroios & 1.378 & 2.587 \\
\hline 4 & Santo António & 1.174 & 4.083 \\
\hline 5 & São Vicente & 1.149 & 2.738 \\
\hline 6 & Estrela & 780 & 3.051 \\
\hline 7 & Avenidas Novas & 387 & 3.070 \\
\hline 8 & Parque das Nações & 337 & 3.351 \\
\hline 9 & Penha de França & 290 & 2.130 \\
\hline 10 & Campo de Ourique & 285 & 2.965 \\
\hline 11 & Belém & 238 & 2.736 \\
\hline
\end{tabular}




\begin{tabular}{|l|c|c|c|}
\hline 12 & Alcântara & 183 & 2.271 \\
\hline 13 & Alvalade & 157 & 2.957 \\
\hline 14 & Areeiro & 146 & 2.550 \\
\hline 15 & Ajuda & 111 & 2.259 \\
\hline 16 & Campolide & 102 & 2.469 \\
\hline 17 & São Domingos de Benfica & 81 & 2.614 \\
\hline 18 & Lumiar & 72 & 2.352 \\
\hline 19 & Olivais & 72 & 1.750 \\
\hline 20 & Beato & 44 & 1.700 \\
\hline 21 & Benfica & 37 & 2.094 \\
\hline 22 & Marvila & 37 & 1.483 \\
\hline 23 & Carnide & 17 & 2.572 \\
\hline 24 & Santa Clara & 06 & 1.739 \\
\hline
\end{tabular}

Fonte dos dados: PINTO, 2018 (valor do metro quadrado); GOMES, 2018 (número de alojamentos). Organizado pelo autor.

A interpretação que podemos tirar do quadro refere-se a um valor médio alto para toda a cidade de Lisboa, até mesmo porque, embora haja esse recorte espacial limitado pelo administrativo, há uma continuidade do tecido urbano para outros municípios da região metropolitana, exceção à direção ao Rio Tejo. Há evidências de que tais continuidades urbanas trazem consequências quanto ao valor médio do metro quadrado, de acordo com a vizinhança e outros fatores. No quadro podemos verificar que nas seis freguesias históricas de Lisboa encontra-se o maior número de alojamentos disponíveis e que estas são coincidentes com aquilo que denominamos área central da cidade e as áreas mais próximas. Esse é o caso das freguesias de Misericórdia e Santa Maria Maior, onde se encontra o maior número de alojamentos, assim como estas duas freguesias apresentam valores que as colocam entre as que detêm o maior valor por metro quadrado na cidade. Seguem essa tendência as freguesias de São Vicente, Santo Antônio e a de Arroios, embora com classificações diferentes entre o valor do metro quadrado e a disponibilidade de alojamentos. A freguesia da Estrela apresenta um valor do metro quadrado elevado e é considerada uma freguesia histórica, no entanto o número de alojamentos é inferior ao existente nas suas congêneres. A hipótese mais provável é de que a inexistência de linha de metrô nessa freguesia possa ser um fator a ser considerado para o menor número de alojamentos. A freguesia de Santo Antônio representa o maior valor por metro 
quadrado da cidade, inflacionado pelo Bairro Alto e pela zona hoteleira de Lisboa junto à Avenida da Liberdade, ambos inseridos nessa freguesia. A freguesia de Arroios, considerada também histórica, possui um número expressivo de alojamentos locais, mas com valor menor no metro quadrado que as anteriores.

Por outro lado, verifica-se que fora dessa área do centro histórico serão as freguesias de classe média da cidade de Lisboa que irão apresentar os maiores valores por metro quadrado e também um número considerável de habitações para alojamento local, com destaque para o Parque das Nações e as Avenidas Novas. Outras freguesias aparecerão com valor do metro quadrado elevado, mas com menor oferta de alojamentos locais, como Alvalade e Campo de Ourique. Destaca-se também a freguesia de Belém, que detém aspectos histórico-arquitetônicos importantes e com um valor do metro quadrado elevado, no entanto apresenta um número mais reduzido na oferta de imóveis para alojamento local, sendo que a falta de linhas de metrô pode explicar essa menor oferta, mesmo havendo outras formas de transporte público. É evidente que o quadro não é totalmente correspondente, no entanto afigura-se uma proximidade das freguesias mais valorizadas com aquelas que recebem o maior número de unidades de alojamento local da cidade, o que tem significado a expulsão dos antigos moradores dessas freguesias.

$O$ estudo [referido na reportagem] aponta que o centro da cidade tem vindo a perder população desde a década de 40, altura em que aqui viviam 160 mil pessoas. Hoje são 40 mil os residentes nas zonas mais antigas de Lisboa. E existe um caldeirão de fatores que impulsionaram esta mudança: o carácter histórico e valor do património; a forte presença de prédios devolutos ou degradados; a predominância do arrendamento como forma de ocupação; as tipologias arquitetônicas que facilmente se adaptam a alojamento turístico; a presença de imóveis de grande dimensão; a requalificação do espaço público; e o envelhecimento dos residentes. A tudo isto juntou-se a chegada de residentes estrangeiros com maior poder de compra e benefícios fiscais. vii

É frequente o número de reportagens na cidade de Lisboa e em Portugal sobre a perda de população, principalmente nas freguesias históricas. Em 2016 já aparecia em reportagem que os presidentes das Juntas de Freguesia da Misericórdia, Santa Maria Maior e São Vicente exigiam à Câmara de Lisboa restrições ao alojamento local e ao turismo, para estancar a perda de população. Conforme os presidentes dessas freguesias, a proliferação desenfreada dos alojamentos locais é a principal causadora da perda de população no centro histórico. viii 
Em fevereiro de 2018 foi publicado em "TSF Rádio Notícias" o registro da Vereadora Paula Marques que diz respeito ao centro histórico e o desalojamento de famílias. Informa que a Câmara de Lisboa irá lançar um concurso direcionado à população que está em situação de perda comprovada de habitação, principalmente aquela mais vulnerável em idade e rendimentos. Serão disponibilizados 100 imóveis pertencentes à Câmara de Lisboa a moradores que tenham perdido seu local de habitação para o alojamento local. Essa medida abrangerá as quatro freguesias do centro histórico da capital: Santa Maria Maior, São Vicente, Misericórdia e Santo António. ix

Outro elemento, além do turismo e do alojamento local, que tem impactado o mercado imobiliário das principais cidades portuguesas refere-se aos chamados "vistos gold". Uma lei aprovada em 2012 permite que todo cidadão de outro país, fora da comunidade econômica europeia, que faça um investimento em Portugal igual ou superior a 500 mil euros, receba o direito de um visto temporário de residência. Passados seis anos, pode requerer a cidadania portuguesa e, consequentemente, europeia. Com isso, tem havido procura expressiva de pessoas oriundas de países como o Brasil, pela facilidade da língua, assim como de outras nações, como a China, que vêm investindo no mercado imobiliário. Registre-se que outros países que permitem essa modalidade de visto, como a Grã-Bretanha, além de exigir um valor bem maior, impedem que tal investimento seja no mercado imobiliário. Para aqueles indivíduos que detêm patrimônio, representa um alto negócio de investimento, já que o mercado imobiliário das maiores cidades portuguesas está em alta e com risco poderia representar outro tipo de negócio ligado a comércio ou serviços. ${ }^{\mathrm{x}}$ Conforme a mesma reportagem, esse regime já possibilitou que mais de seis mil pessoas solicitassem o visto nessa modalidade, e seus investimentos já atingem 3,9 bilhões de euros, 95\% em imóveis, o que contribuiu para o boom imobiliário nas cidades de Lisboa e Porto. Os brasileiros são os principais investidores, retendo a parcela de $21 \%$ em 2017.

Note-se que o aumento significativo do turismo na cidade de Lisboa e o consequente desalojamento da população local não representa um mero acaso, mas é resultado da mudança de políticas internas em Portugal que visaram à atração de investimentos externos no mercado imobiliário. Por outro lado, há uma conjuntura internacional de rearranjo do fluxo de turistas para o sul da Europa que antes se 
direcionavam para outros locais como o norte da África e hoje redescobriam a costa portuguesa e as cidades que contém, o que inclui sua capital como um dos principais destinos.

\section{CONSIDERAÇÕES FINAIS}

O processo de valorização do mercado imobiliário na atualidade não tem limites e busca de forma incessante a apropriação de forma a obter maiores rendimentos, seja na compra e venda, seja nas diferentes formas de arrendamento. 0 que ocorre hoje em Lisboa, assim como na cidade do Porto, são realidades muito presentes há mais tempo em cidades como Veneza e Barcelona. O que as diferencia são os novos elementos desencadeadores desse processo, embora o alojamento local esteja presente em todas elas e cause perturbações na vida de seus moradores.

No caso português e de Lisboa, o turismo representa na atualidade uma importante fonte de renda para a cidade e o país, no entanto isso não se reflete, por exemplo, no aumento do salário mínimo nacional, que tem apresentado índices muitíssimo inferiores aos valores das rendas dos imóveis, assim como ao valor de compra e venda. Tais processos, impulsionados pelo movimento crescente de turistas, pelas formas mais fáceis e baratas de hospedagem, como hostels e alojamento local, possibilitam o aumento da escassez de imóveis aliado a conjunturas como as do "visto gold" e a atração de novos moradores às velhas freguesias históricas. Não há legislação na atualidade, além de propostas de difícil execução, que possam regrar os limites de cada freguesia na disponibilização de imóveis para moradia em arrendamento anual e moradia transitória para turistas de curto ou médio prazo.

Entende-se que normalizar essa situação será um processo muito difícil de concretizar, pelos elementos envolvidos, pela ideia predominante de livre mercado e os valores muito maiores que o alojamento local proporciona aos seus proprietários em relação ao aluguel anual. Medidas discutidas na Assembleia da República, como o financiamento para novos investimentos por parte dos proprietários a fim de baratear o valor de arrendamento, podem ser de difícil concretização, pois os proprietários somente irão investir na construção de novos imóveis e na reformulação dos antigos se houver garantia no mercado de bons rendimentos nos arrendamentos ou numa 
futura venda desses bens. Desejar investimento a fim de propiciar arrendamentos mais baratos foi e continuará sendo sempre um desafio para os Estados democráticos nesse difícil equilíbrio entre regramento estatal e mercado privado da moradia. Como resultado desse processo, temos hoje um aumento muito significativo do custo de vida na cidade de Lisboa, encarecido pelos aumentos do custo de moradia, já que os velhos imóveis de arrendamento anual cada vez mais cedem espaço para o alojamento local, através de empresas como Booking e Air Bnb. Estas disponibilizam aos seus usuários fácil acesso à locação, através da tela de um telefone celular para clientes no mundo todo. Trata-se de uma concorrência extremamente desleal para com a população portuguesa que historicamente sempre teve a locação como forma tradicional de moradia. Para os proprietários houve uma mudança para melhor, pois viram triplicar e quadruplicar seus ganhos mensais, devido ao alto fluxo de turistas, principalmente nos bairros históricos. Estes vêm se tornando "não lugares", ou seja, bairros com patrimônio material significativo, mas sem a população local que thes dava vida. Hoje, em alguns deles encontramos turistas que encontram outros turistas nas ruas, nos bares e restaurantes, e passam a constituir os transeuntes dos velhos bairros da capital portuguesa, em espaços cada vez mais adaptados às suas necessidades.

\section{REFERÊNCIAS}

CENTRO histórico perdeu 120 mil pessoas, diz estudo da Misericórdia, Santa Maria Maior e São Vicente. Time Out, 22 jan. 2018. Disponível em: https://www.timeout.pt/lisboa/pt/noticias/centro-historico-perdeu-120-mil-pessoas-diz-estudo-damisericordia-santa-maria-maior-e-sao-vicente-012218. Acesso em: 28 set. 2018.

FERNANDES, F. As luzes e as sombras do turismo de Lisboa. Eco, 20 set. 2017. Disponível em: https://eco.pt/2017/09/20/as-luzes-e-as-sombras-do-turismo-de-lisboa/. Acesso em: 28 set. 2018.

FREGUESIAS do centro de Lisboa exigem à Câmara e ao governo limites ao turismo. Sapo24, 25 fev. 2016. Disponível em: https://24.sapo.pt/atualidade/artigos/freguesiasdo-centro-de-lisboa-exigem-a-camara-e-ao-governo-limites-ao-turismo. Acesso em: 28 set. 2018.

GANT, Agustin Cócola. Holiday rentals: the new gentrification battlefront. Sociological Research Online, v. 21, n. 3, 2016. Disponível em: http://www.socresonline.org.uk/ 21/3/10.html. Acesso em: 27 set. 2018. 
GANT, Agustin Cócola; PARDO, Daniel. Resisting tourism gentrification: the experience of grass-roots movements in Barcelona. Urbanistica, n. 13, maio-ago. 2017. Quaderni AntiGentrification nelle Città (Sud) Europee. Disponível em: http://www.urbanisticatre.uniroma3.it/dipsu/. Acesso em: 27 set. 2018.

GANT, Agustin Cócola. Struggling with the leisure class: tourism, gentrification and displacement. Cardiff, 2018. Thesis [Ph.D. Philosophy] - School of Geography and Planning, Cardiff University.

GOMES, Paulo Zacarias. Aluga-se Portugal. Visão, n. 1322, p. 36-45, 5-11 jul. 2018. Semanal.

GONÇALVES, Jorge. Reabilitação urbana: oportunidades econômicas, emprego e competências. Lisboa: Atelier Gráficos à Lapa, 2003.

LISBOA tenta travar saída de moradores do centro histórico. TSF Rádio Notícias, 29 dez. 2017. Disponível em: https://www.tsf.pt/sociedade/interior/lisboa-tenta-travar-saida-demoradores-do-centro-historico-9015090.html. Acesso em: 27 set. 2018.

MACHADO, Aquilino. Os espaços públicos da exposição do mundo português e da Expo 98. Lisboa: Parque Expo '98, 2006. Col. Expoentes.

MENDES, Luís. A nobilitação urbana no Bairro Alto: análise de um processo de recomposição sócio-espacial. Finisterra, v. 41, n. 81, p. 57-82, 2006. Disponível em: https://revistas.rcaap.pt/finisterra/article/view/1462. Acesso em: 28 set. 2018.

PAVEL, Fabiana. Transformação urbana de uma área histórica: o Bairro Alto: reabilitação, identidade e gentrificação. Lisboa, 2015. Tese [Doutorado em Arquitetura] - Faculdade de Arquitectura, Universidade de Lisboa.

PINTO, Sônia. Casas: há zonas em Lisboa cujo preço por $\mathrm{m}^{2}$ ultrapassa os 4 mil euros. Inevitável. Lisboa, 1 ago. 2018, p. 16-17. Diário.

POR QUE os 'vistos gold', muito visados por brasileiros, viraram centro de polémica em Portugal. BBC News Brasil, 22 set. 2018. Disponível em: https://noticias.uol.com.br/ultimas-noticias/bbc/2018/09/22/por-que-os-vistos-douradosmuito-visados-por-brasileiros-viraram-centro-de-polemica-em-portugal.htm. Acesso em: 28 set. 2018.

ROMANA, Xerez. Dinâmicas do território: centralidade e gentrificação na cidade de Lisboa. Lisboa, 2008. Dissertação [Mestrado em Sociologia] - Instituto Superior de Ciências Sociais e Políticas, Universidade Nova de Lisboa.

SMITH, Neil. The new urban frontier: gentrification and the revanchist city. London: Routledge, 1996.

SMITH, Neil. A gentrificação generalizada: de uma anomalia local à regeneração urbana como estratégia urbana global. In: ZACHARIESEN, Catherine (org.). De volta à cidade: dos processos de gentrificação às políticas de revitalização urbana. São Paulo: Annablume, 2006. 


\begin{abstract}
${ }^{i}$ As with every ideology, there is a real and partial if distorted basis for the treatment of gentrification as a new urban frontier. The frontier represents an evocative combination of economic, geographical and historical advances, and yet the social individualism pinned to this destiny is in one very important respect a myth.
\end{abstract}

ii It is a snowball process in which the area loses residents and excludes potential ones from the possibility of moving in. It leads to a form of collective displacement never seen in classical gentrification, that is to say, to a substitution of residential life by tourism.

iii A organização administrativa de Lisboa (Lei n. 56/2012, de 8 de novembro), alterada pela Lei n. 85/2015, de 7 de agosto), criou um novo mapa da cidade e baseia-se numa estratégia de modernização do modelo de governo autárquico, descentralizando competências administrativas para as Juntas de Freguesia. Implicitamente está a alteração geográfica das atuais freguesias, que passam de 53 a 24, agregando algumas, delimitando de outra forma e até criando uma nova área administrativa da cidade - o Parque das Nações. Fonte: Câmara Municipal de Lisboa.

iv Put simply, as short-term rentals are an appealing business opportunity, long-term residents represent a barrier to capital accumulation.

$\checkmark$ The new ambiance that modern stores bring to districts is welcomed by residents and traditional users. Residents see a contemporary retail environment in their area, even if they do not intend to shop at these stores or are unable to afford their products. As suggested for residents with fewer resources, the opening of these new stores does not benefit them because they are unable to afford what they sell. In addition, this scenario can gentrify the entire area by raising rents and causing the displacement of the few stores that the least well-off can afford to shop at.

vi Antiga Freguesia do Bairro Alto até 2012, hoje corresponde a um fragmento da Freguesia de Santo Antônio, por sinal a que detém o maior valor por metro quadrado da cidade, conforme Tabela 1.

vii www.timeout.pt/lisboa/pt/noticias/centro-historico. Acesso em: 27 set. 2018.

viii https://24.sapo.pt/atualidade/artigos/freguesias-do-centro-de-lisboa-exigem-a-camara-e-ao-governolimites-ao-turismo. Acesso em: 28set. 2018.

${ }^{i x}$ https://www.tsf.pt/sociedade/interior/lisboa-tenta-travar-saida-de-moradores-do-centro-historico9015090.html. Acesso em: 27 set. 2018.

${ }^{x}$ https://noticias.uol.com.br/ultimas-noticias/bbc/2018/09/22/por-que-os-vistos-dourados-muito-visados-porbrasileiros-viraram-centro-de-polemica-em-portugal.htm. Acesso em: 20 set. 2018. 